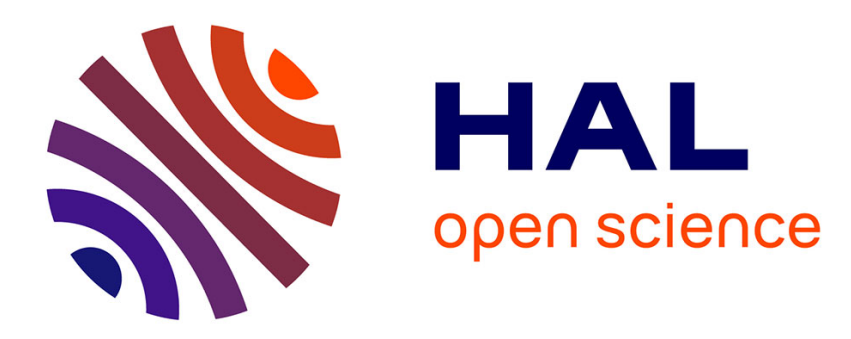

\title{
What Does Nasal Cavity Size Tell us about Functional Nasal Airways? \\ Yann Heuzé
}

\section{To cite this version:}

Yann Heuzé. What Does Nasal Cavity Size Tell us about Functional Nasal Airways?. Bulletins et Mémoires de la Société d'anthropologie de Paris, 2019, 31 (1-2), pp.69-76. 10.3166/bmsap-2018-0011 . hal-02322344

\section{HAL Id: hal-02322344 \\ https://hal.science/hal-02322344}

Submitted on 11 Jan 2021

HAL is a multi-disciplinary open access archive for the deposit and dissemination of scientific research documents, whether they are published or not. The documents may come from teaching and research institutions in France or abroad, or from public or private research centers.
L'archive ouverte pluridisciplinaire HAL, est destinée au dépôt et à la diffusion de documents scientifiques de niveau recherche, publiés ou non, émanant des établissements d'enseignement et de recherche français ou étrangers, des laboratoires publics ou privés. 
What does nasal cavity size tell us about functional nasal airways?

Qu'est-ce que la taille de la cavité nasale nous dit sur les voies aériennes nasales?

Yann Heuzé

Univ. Bordeaux, CNRS, MCC, PACEA, UMR5199, Bordeaux Archaeological Sciences Cluster of Excellence, Pessac, France

Abbreviated title: Nasal cavity vs. nasal airways

Key words: air conditioning, respiratory energetics, computed tomography, in vivo Mots clés : conditionnement de l'air, dimension énergétique de la respiration, tomographie, in vivo

Postal address: Yann Heuzé, UMR 5199 PACEA, Allée Geoffroy Saint Hilaire Bat. B8 CS 50023, 33615 Pessac Cedex, France.

Email: yann.heuze@u-bordeaux.fr; yannheuze@gmail.com

Phone: +33556003741

$\mathrm{YH}$ is supported by the research program LaScArBx from the French National Research Agency (ANR) and its program "Investissements d'avenir" [ANR-10-LABX-52] 


\begin{abstract}
Studies on dry human skulls have shown that nasal cavity (NC) morphology varies according to ecogeographic factors. These findings have been used by some authors to interpret the facial morphology of Neanderthals. However, respiratory and air conditioning functions are primarily carried out by the nasal airways (NA) which are delimited by mucosa. The aims of this study were to test whether: 1) NC volume (V) and surface area to volume ratio (SA/V) are proportional to NA counterparts; 2) males NC and NA measurements are larger than those of females; 3 ) the centroid size (CS) of a set of landmarks measured on NC provides a reliable proxy for NC V. Head CT images of adults $(N=30)$ who consulted at the University Hospital of Bordeaux were retrospectively selected. NA were defined by segmenting the lumen corresponding to the functional volume. NC was defined by adding to NA the soft tissues delimited by the bones forming NC. The coordinates of 16 landmarks measured on NC bones were recorded. A rather low correlation was found between NA and NC V while NA SA/V and NC SA/V were not correlated. No significant differences between male and female NA and NC measurements were found. A rather low correlation was found between NCV and NC CS. If these preliminary results were to be confirmed by future studies, results using NC as a proxy for NA focusing on air conditioning and respiratory energetics might need to be re-interpreted.
\end{abstract}




\section{Résumé}

Plusieurs études sur des crânes secs humains ont révélé que la morphologie de la cavité nasale (NC) varie selon des facteurs écogéographiques. Ces résultats ont été utilisés par certains auteurs pour interpréter la morphologie faciale des Néandertaliens. Cependant, les fonctions respiratoires et le conditionnement de l'air sont assurés en premier lieu par les voies aériennes nasales (NA) qui sont délimitées par une muqueuse. Les buts de cette étude étaient de tester si : 1) le volume (V) et le rapport de l'aire surfacique sur le volume (NA/V) de NC sont proportionnels à ceux de NA;2) NC et NA sont plus grandes chez les hommes ; 3) la taille centroïde (CS) représente un indicateur fiable du V de NC. Des images tomographiques d'individus adultes $(\mathrm{N}=30)$ du $\mathrm{CHU}$ de Bordeaux ont été sélectionnées de manière rétrospective. NA étaient définies par la segmentation du lumen correspondant au volume fonctionnel. NC était définie en ajoutant à NA les tissus mous délimités par les os formant NC. Les coordonnées de 16 landmarks mesurés sur les os de NC ont été enregistrées. Une faible corrélation a été trouvée entre les $V$ de NA et NC tandis qu'aucune n'a été identifiée entre NA SA/V et NC SA/V. Aucune différence significative entre hommes et femmes n'a été trouvée. Une corrélation relativement faible a été identifiée entre NC V et NC CS. Si ces résultats préliminaires venaient à être confirmés par de futures études, les résultats utilisant NC comme un proxy pour NA pour l'étude des capacités respiratoires et du conditionnement de l’air devraient être réinterprétés. 


\section{INTRODUCTION}

Several studies on dry skull materials of different human populations from different latitudes have shown that nasal cavity (NC) morphology varies according to ecogeographic factors, such as temperature and humidity. Historically, the relationships between climate and NC size and proportions was established by studies focusing primarily on the dimensions of the nose and the nasal aperture [1-7]. Later on, studies taking into account the entire NC confirmed this relationship, particularly for populations living in extremely cold climates [8-11]. Populations living in cold climates tend to display a narrower nasal aperture, sagittally enlarged NC, and increased surface-area-to-volume ratio (SA/V) of NC, resulting in a greater air conditioning capacity $[9,12-16]$. On the other hand, a recent paper by Maddux et al. [17] indicates that the internal nasal fossa is the only component of the nasal complex (i.e., external pyramid, nasal aperture, internal nasal fossa, and nasopharynx) which displays an ecogeographic pattern of variation consistent with adaptation to climatic conditions. Because European Neanderthals lived during periods characterized by glacial conditions, many aspects of their morphology, including facial skeletal traits (e.g. nasal cavity and paranasal sinuses), have been interpreted as adapted to cold climate [e.g. 18]. However, genetic drift has been shown to be able to account for several of these traits [e.g. 19]. Consequently, the meaning of Neanderthal skeletal morphology is still debated.

The NC is a negative space delimited by bones housing the nasal airways (NA). As such, NC is the gateway to the respiratory system [20] and indirectly participates in inspired and expired air conditioning. NC displays a variable and complex morphology based on the shape and size of the aspects of the bones forming that negative space; the maxilla, nasal, palatine, vomer, sphenoid, frontal, ethmoid, and lacrimal bones. The superior, middle, and lower nasal turbinates or conchae contribute to the complexity of NC morphology. The quantity of inspired air depends on NC size and shape and particularly of its height and width, especially at its entrance and exit points (i.e. piriform aperture and the choanae, 
respectively) [21,22]. Consequently, NC morphology likely influences respiratory energetics. The effectiveness of air conditioning is also related, at least partially, to NC morphology, particularly to NC length (e.g. [8]) and SA/V (e.g. [9]).

However, the functional negative space primarily responsible for air conditioning is represented by the NA. NA are delimited by mucosa and housed within the NC. Because of its dense vascularization, NA mucosa experiences variation in thickness depending on several possibly interrelated factors, including blood pressure, temperature, humidity, and nasal cycle $[9,23,24]$. This results in fluctuations in the level of congestion (reduced volume), or its opposite condition, decongestion, exhibited by NA. Obviously, only studies based on living individuals allow NA morphology to be analyzed and quantified, and computed tomography (CT) images offer appropriate material for that purpose. Very few studies quantifying NA morphology have been published to date. One such study is that of Yokley [9] in which the author uses a 2D approach for in vivo CT images to compute the ratio between the perimeter and area of one coronal section through the nasal passages. These measurements were done twice per specimen, one with NA partially congested by the nasal mucosa and another with nasal airways fully decongested after virtually removing the nasal mucosa. Only the measurements of the fully decongested NA were found to correlate with ecogeographic variables. However, the results obtained with fully decongested NA are somewhat artificial since they are based on the hypothesis that the thickness of the mucosa is null, which effectively results in measuring NC.

Therefore, the following question still remains: what does NC size (i.e. volume, V) tell us about functional NA? In other words, what are the differences between NC and NA size when the mucosa is taken into account? The aim of the present study is to quantify NC size and air conditioning potential (i.e. $\mathrm{SA} / \mathrm{V}$ ) and to compare them with those of NA. Since NC volume is often approximated by the centroid size (square root of the sum of squared distances of a set of landmarks from their centroid, CS) of a set of anatomical landmarks measured on the bones forming the NC, we also explore whether CS is a reliable 
proxy for NC volume. Three working hypotheses were tested throughout the present study: (H1) NCV, surface area (SA), and SA/V are proportional to NA counterparts; $(\mathrm{H} 2)$ because of larger body and lean mass, males display larger NC and NA than females; $(\mathrm{H} 3)$ CS of a set of anatomical landmarks measured on the bones forming the NC provides a reliable proxy for NC volume.

\section{MATERIALS AND METHODS}

Head CT angiogram images of adult patients who consulted at the emergency room of the University Hospital of Bordeaux have been selected for the purpose of this study (slice thickness: $0.625 \mathrm{~mm}$ ). The following patients were systematically excluded: those younger than 18 years, older than 59 years, with major facial skeletal dysmorphology, under respiratory assistance, or with obstructed nasal airways. Patients imaged with their mouth open were also excluded to avoid potential bias linked to mouth breathing. Fifteen men and fifteen women have been included in our sample (mean age $=31.8$ years; SD

$=11.0$ years $)$. There was no significant age differences between males and females $(t=-0.0652, p=$ 0.9502). All images were collected retrospectively and anonymized. Only the sex and exact age at exam were kept. This study has been reviewed and approved by the Univ. Bordeaux IRB (Comité de Protection des Personnes Sud-Ouest et Outre Mer III).

First, the NA were defined by segmenting the lumen corresponding to the airway's functional volume and were delimited anteriorly by the nasal aperture and posteriorly by the choanae (Fig. 1A, 1C). Because of the difficulty in objectively determining where the NA end and where the ethmoidal cells begin, the latter were included in what is defined as NA in the present study. The NC was defined by segmenting both the lumen (i.e., NA) and the soft tissues covering the bones forming the NC (from anterior nasal aperture to choanae) (Fig. 1B, 1D). Though segmenting nasal conchae can sometimes be challenging (e.g. [25]), they were segmented as bone and not included in the computation of NC measurements. NA and NC were segmented in the transverse plane and inspected in the coronal and 
sagittal planes (Fig. 1). Both NC and NA were closed on each transverse slice anteriorly by a line joining the two aspects of the maxilla or the nasal bones forming the nasal aperture, and posteriorly by a line joining the distal walls of the choanae formed by the sphenoid and passing through the most posterior aspect of the vomer (Fig. 1). For NA and NC, both left and right sides were considered to avoid potential effects of nasal cycle. Nasal cycle is characterized by recurrent variation in air mass-flow partitioning between the right and left airways, which alternatively display different level of mucosa congestion, enabling each passageway to alternatively take turns in either predominantly undertaking the airconditioning or mucus clearance roles [24]. Because of the central aspect of the segmentation process in the present study, the repeatability of the protocol was quantified by measuring five individuals twice (one set of measure at the beginning of the data collection, one set in the end). The results are presented in table 1 and show that the intra-observer error is negligible.

Additionally, 16 three dimensional landmarks were measured on bone (Fig. 2). The landmarks' 3D coordinates were then analyzed with geometric morphometrics using general Procrustes superimposition $[26,27]$. Centroid size (CS, the square root of the summed squared distances of each landmark to the centroid) was used as a proxy for NC size.

Next, because it has been shown that airflow in the lower and middle meatus account for over $80 \%$ (50\% and $30 \%$ respectively) of the total nasal airflow [28], hormion and the anteriormost point on the left and right nasomaxillary sutures were selected to define a plane that was subsequently used to separate the upper meatus from the middle and lower meatus. Only the latter portion was then studied. Though this plane might not be ideal, it was the one among the several planes tested passing through the measured landmarks, which gave the most satisfactory results for the separation of the upper meatus from the middle and lower meatus.

The ratio SA/V was computed for both the NC and NA as it represents a relevant proxy for air conditioning potential. 
Finally, to broadly describe NC relative dimensions, linear measurements accounting for NC length (from nasomaxillary suture, left to choanal roof, left) and NC width (mean between inter-lower turbinate base and inter-alare distances) were recorded (Fig. 2). NC height was measured from, superiorly, the anteriormost point of the inferior surface of the cribriform plate taken on a slice parallel to the mid sagittal plane (passing through nasale, anterior nasal spine, posterior nasal spine), to, inferiorly, the perpendicular projection of the superior point onto the nasal surface of the maxilla. This slice was the closest to the midsagittal plane for which the vomer was not visible anymore to avoid artificial reduction of NC height (Fig. 2). Larger NC height and width are expected to facilitate volumetric intake of air, while NC length has no influence. However larger NC length is expected to facilitate air conditioning by increasing air resident time.

T-tests with Monte Carlo permutations $(n=9,999)$ and Pearson's correlation coefficients with Monte Carlo permutations ( $n=9,999$ ) were used to test our hypotheses. For these tasks, the software package PAST was used [29].

\section{RESULTS}

\section{$\underline{\mathrm{H} 1:} \mathrm{NC} \mathrm{V}, \mathrm{SA}$, and SA/V are proportional to NA counterparts}

When considering the entire NC and NA, including the ethmoidal cells, there was no significant correlation between NA V and NC V $\left(R^{2}=0.0445, p=0.2625\right)$, though there was a significant correlation between NA SA and NC SA $\left(R^{2}=0.2305, p=0.0075\right)$ (Table 2$)$. There was no significant correlation between NA SA/V and NC SA/V $\left(R^{2}=0.0065, p=0.7066\right)$ (Table 2$)$. NA SA/V was characterized by a higher dispersion (coefficient of variation: $c_{v}=0.223$ ) than NC SA $/ \mathrm{V}\left(c_{v}=0.144\right)$.

When only considering the lower two thirds of NA and NC, a significant correlation, though relatively low, was found between NA V and NC V $\left(R^{2}=0.1408, p=0.0349\right)$ and another between NA SA and NC SA $\left(R^{2}=0.7066, p=0.0001\right)$ (Table 2$)$. There was no significant correlation between NA SA/V and NC SA/V 
$\left(R^{2}=0.0078, p=0.6234\right)$ (Table 2$)$. NA SA/V was characterized by a higher dispersion $\left(c_{v}=0.313\right)$ than NC $\mathrm{SA} / \mathrm{V}\left(c_{\mathrm{v}}=0.131\right)$

\section{$\underline{\mathrm{H} 2: \text { Males display larger NC and NA than females }}$}

When considering the entire NA and NC, no significant differences were found between males and females for NA V $(t=1.2721, p=0.2144)$, NA SA $(t=-0.1336, p=0.8982)$, NA SA $/ \mathrm{V}(t=-2.0569, p=$ $0.0510), \operatorname{NCV}(t=-1.8106, p=0.0792), \mathrm{NCSA}(t=-0.1429, p=0.2599)$, nor NC SA $/ \mathrm{V}(t=0.1149, p=$ 0.9613) (Table 3). When only considering the lower two thirds of NA and NC, there was no significant differences between male and female NA V $(t=1.1018, p=0.2736)$, NA SA $(t=-0.1778, p=0.8584)$, NA $\mathrm{SA} / \mathrm{V}(t=-1.4302, p=0.1575), \mathrm{NC} V(t=-1.4307, p=0.1656), \mathrm{NC} \mathrm{SA}(t=-0.5453, p=0.5925)$, or NC SA/V ( $t=0.9974, p=0.3319$ ) (Table 3). While males displayed overall larger measurements than female, females displayed larger NA V, either considering the entire NA or only the lower two thirds.

Though males displayed overall larger NC linear measurements, no significant differences between male and female NC height $(t=1.2981, p=0.2024)$, NC width $(t=0.8589, p=0.3950)$, nor NC length $(t=$ 0.9827, $p=0.3301$ ) were found (Table 4).

\section{H3: CS of NC provides a reliable proxy for NC volume}

There was a significant, though rather low, correlation between NCV and NC CS, either when considering the entire NC $\left(R^{2}=0.3597, p=0.0005\right)$ or only NC lower two thirds $\left(R^{2}=0.1944, p=0.0147\right)$. Male NC CS was significantly larger than female NC CS only when considering the entire NC $(t=2.5138, p=0.0180)$. When considering the lower two thirds of NC, there was no significant differences between male and female NC CS $(t=1.9556, p=0.0606)$.

\section{DISCUSSION}


Based on our results, $\mathrm{H} 1$, stating that $\mathrm{NCV}, \mathrm{SA}$, and $\mathrm{SA} / \mathrm{V}$ are proportional to NA counterparts, could only be supported with some limitations. Indeed, only the volume of the lower two thirds of NC was significantly correlated with that of NA. However this correlation appeared relatively low $\left(R^{2}=0.1408\right)$. Though the correlation was high for SA between NA and NC, this was not the case for SA/V which is commonly used as a proxy for air conditioning potential. Consequently, it might be more appropriate to consider only the lower and middle meatus when measuring NC. This is consistent with the fact that NA lower two thirds account for over $80 \%$ of the total nasal airflow [28]. However, it appeared that interpolation made on air conditioning potential on the basis of NC SA/V could be problematic.

This study revealed no significant differences between male and female NA V, NC V, NA SA, NC SA, NA SA/V, or NC SA/V, either considered as a whole or for only the lower two-thirds. Consequently, H2, stating that males display larger NC and NA than females, should be rejected. Because NC height and width primarily constraint volumetric intake of air, both were expected to be significantly larger in males. However, none was significantly larger in males than in females. Overall, these results bring little support to the hypothesis that, due to larger body size and lean mass, male NC and NA are larger than female NC and NA. However, these results are based on a rather small sample size $(n=30)$ and it is expected that with a larger sample some of these differences might surpass the significance threshold.

The 16 anatomical landmarks measured in the present study on NC correspond to the measurable landmarks on CT images from a list of landmarks classically measured on dry skulls in comparable studies [e.g. $8,10,11,22]$. Based on our results, the CS of such a landmark configuration appears to be a relatively poor proxy for NC volume especially when considering the lower two thirds of NC $\left(R^{2}=0.1944\right)$. Thus, $\mathrm{H} 3$, stating that $\mathrm{CS}$ of NC provides a reliable proxy for NC volume, should be rejected. It is unlikely that the rather complex geometry of NC could be captured in an optimal manner by these external landmarks that might over-simplify NC complex geometric properties. Consequently, the measure of NC volume might be the only reliable way to quantify NC size. 
NA appears much more variable than NC. One obvious explanatory factor of this inter- and intraindividual variation is the mucosa itself, which varies in volume and consequently contributes to variation in NA volume as well. In contrast, for the same individual, the NC volume remains constant. This study attempted to control for a maximum of factors influencing mucosa congestion/decongestion state. First, only patients breathing by the nose, without respiratory assistance, and with their mouth closed during the CT exam were selected. Second, a relative rest state was assumed at the time of imaging (i.e., no engagement in major physical activities), as well as relatively homogeneous environmental conditions as temperature and humidity levels were controlled by air conditioning. Third, nasal cycle was taken into account by measuring the right and left NA rather than just one side. Since the present study focused on rest state condition, considering the fully decongested NA did not appear as a relevant approach. Note that during physical exercise, the nasal mucosa decongests almost to the same level as after using topical decongestant [30], though a significant part of respiration is carried out by the mouth. The level of stress experienced by the patients could, however, not be controlled. Despite all these precautions taken, NA SA/V was twice to thrice more variable than NC SA/V. This result is in agreement with that obtained by Yokley [9] in 2D showing that, when the mucosa was taken into account (i.e., not fully decongested), variation in SA/V was too substantial to observe a significant difference for SA/V between individuals of European descent and African descent.

Another explanatory factor to the overall low correlation existing between NA and NC measurements is the anatomical complexity of the nasal conchae and the acknowledged difficulty to segment them on $\mathrm{CT}$ images. This difficulty is linked to the complex geometry of the nasal conchae and the surrounding soft tissues and fluids [25]. While the nasal conchae were segmented as bone and consequently not taken into consideration when computing NC measurements, it is possible that for some individuals an imperfect segmentation resulted in the inclusion of small parts of the nasal conchae in NC measurements. The fact that males displayed larger mean NC volumes but smaller mean NA volumes 
compared to females (Tables 3 ) could suggest that males have larger nasal conchae potentially associated with larger mucosa volumes.

The results of the present preliminary study seem to challenge the validity of the often assumed or implied correlation between NA and NC size/volume. Because of its relatively small sample size and its methodological limitations (e.g. segmentation of the conchae, mucosa thickness variation), these preliminary results remain to be validated by future studies that will provide a more robust description of the relationship between NA and NC. If these preliminary results were to be confirmed by future studies, results produced by studies based on dry skull materials focusing on air conditioning and respiratory energetics using NC as a proxy for NA might need to be re-interpreted. Studies on these topics including fossils such as Neanderthals, for which the NC is rarely fully conserved, are implicated as well. These future studies will need to use larger in vivo samples, as well as possibly those originating from different regions of the world, to provide more in depth results pertaining to the nature of the relationship between NA and NC morphological variation and co-variation and their implications for air conditioning and respiratory energetics. One key aspect for this future work will be to use imaging parameters optimized for nasal conchae visualization and segmentation to investigate the potential role of the nasal conchae and the overlying mucosa in the differences observed between NC and NA measurements.

\section{ACKNOWLEDGEMENTS}

Y.H. is supported by the research program LaScArBx from the French National Research Agency (ANR) and its program "Investissements d'avenir" [ANR-10-LABX-52]. The author is grateful to Drs. Andrej Evteev, Sébastien Villotte, Lauren Butaric, Christina Nicholas, Jessica Joganic and Christine Couture for interesting discussions on previous versions of this work. Comments from the two reviewers (Drs. Scott 
Maddux and Philipp Gunz, anonymity waived) allowed to improve the overall quality of the manuscript. 


\section{References}

1. Thomas A, Buxton L (1923) Man's nasal index in relation to certain climatic conditions. J R Anthropol Inst 53:92-122

2. Davies A (1932) A re-survey of the morphology of the nose in relation to climate. J R Anthropol Inst 62:337-59

3. Weiner JS (1954) Nose shape and climate. Am J Phys Anthropol 12:615-8

4. Carey J W, Steegmann AT (1981) Human nasal protrusion, latitude, and climate. Am J Phys Anthropol 56:313-9

5. Franciscus RG, Long JC (1991) Variation in human nasal height and breadth. Am J Phys Anthropol 85:419-27

6. Roseman CC (2004) Detecting interregionally diversifying natural selection on modern human cranial form by using matched molecular and morphometric data. Proc Natl Acad Sci U S A 101:12824-9

7. Hubbe M, Hanihara T, Harvati K (2009) Climate signatures in the morphological differentiation of worldwide modern human populations. Anat Rec 292:1720-33

8. Noback ML, Harvati K, Spoor F (2011) Climate-related variation of the human nasal cavity. Am J Phys Anthropol 145:599-614

9. Yokley TR (2009) Ecogeographic variation in human nasal passages. Am J Phys Anthropol 138:11-22

10. Evteev A, Cardini AL, Morozova I, et al (2014) Extreme climate, rather than population history, explains mid-facial morphology of Northern Asians. Am J Phys Anthropol 153:449-62

11. Fukase $H$, Ito $T$, Ishida $H$ (2016) Geographic variation in nasal cavity form among three human groups from the Japanese Archipelago: Ecogeographic and functional implications. Am J Hum Biol 28:34351

12. Churchill SE, Shackelford LL, Georgi JN, et al (2004) Morphological variation and airflow dynamics in the human nose. Am J Hum Biol 16:625-38

13. Doorly DJ, Taylor DJ, Gambaruto AM, et al (2008) Nasal architecture: form and flow. Philos Transact A Math Phys Eng Sci 366:3225-46

14. Holton NE, Yokley TR, Franciscus RG (2011) Climatic adaptation and Neandertal facial evolution: a comment on Rae et al (2011) J Hum Evol 61:624-7

15. Holton N, Yokley T, Butaric L (2013) The morphological interaction between the nasal cavity and maxillary sinuses in living humans. Anat Rec 296:414-26

16. Maddux SD, Yokley TR, Svoma BM, et al (2016) Absolute humidity and the human nose: A reanalysis of climate zones and their influence on nasal form and function. Am J Phys Anthropol 161:309-20 
17. Maddux SD, Butaric LN, Yokley, TR, et al (2017) Ecogeographic variation across morphofunctional units of the human nose. Am J Phys Anthropol 162:103-19

18. Steegmann AT, Cerny FJ, Holliday TW (2002) Neandertal cold adaptation: physiological and energetic factors. Am J Hum Biol 14:566-83

19. Weaver TD (2009) Out of Africa: modern human origins special feature: the meaning of neandertal skeletal morphology. Proc Natl Acad Sci U S A 106:16028-33

20. Enlow DH (1990) Facial Growth 3 Sub edition. Saunders WB Co, Philadelphia 572 p

21. Swift D, Proctor D (1977) Access of air to the respiratory tract. In: Brain J, Proctor D, Reid L (ed) Respiratory defense mechanisms. Dekker M, New York, pp 63-91

22. Bastir M, Rosas A (2013) Cranial airways and the integration between the inner and outer facial skeleton in humans. Am J Phys Anthropol 152:287-93

23. Cauna N (1982) Blood and nerve supply of the nasal lining. In: Proctor D, Andersen I (ed) The nose: upper airways physiology and the atmospheric environment. Elsevier Biomedical Press, New York, pp 45-69

24. White DE, Bartley J, Nates RJ (2015) Model demonstrates functional purpose of the nasal cycle. Biomed Eng OnLine 14

25. Uosyte R, Shaw DJ, Gunn-Moore DA, et al (2015) Effects of fluid and computed tomographic technical factors on conspicuity of canine and feline nasal turbinates. Vet Radiol Ultrasound 56:494502

26. Rohlf F, Slice D (1990) Extensions of the Procrustes method for the optimal superimposition of landmarks. Syst Zool 39:40-59

27. Dryden IL, Mardia KV (1998) Statistical Shape Analysis. Wiley, Chichester 347 p

28. Xiong G, Zhan J-M, Jiang $\mathrm{H}-\mathrm{Y}$, et al (2008) Computational fluid dynamics simulation of airflow in the normal nasal cavity and paranasal sinuses. Am J Rhinol 22:477-82

29. Hammer $\varnothing$, Harper DAT, Ryan PD (2001) PAST: Paleontological Statistics Software Package for Education and Data Analysis. Palaeontologia Electronica 4:1-9

30. Hilberg O (2002) Objective measurement of nasal airway dimensions using acoustic rhinometry: methodological and clinical aspects. Allergy 57 Suppl 70:5-39 


\section{TABLES}

Table 1 Repeatability of the segmentation process of the nasal airways including ethmoidal cells (NA) and nasal cavity (NC) with corresponding volume and surface area ${ }^{a}$. Each individual was segmented twice / Répétabilité de la segmentation des voies aériennes nasales incluant les cellules ethmoïdales (NA) et de la cavité nasale (NC) avec les volumes et aires surfaciques correspondants. Chaque individu a été segmenté deux fois.

\begin{tabular}{lrrrr}
\hline & NA V & NC V & NA SA & NC SA \\
\hline Ind. A_round\#1 & 22.95 & 59.79 & 22.83 & 18.35 \\
Ind. B_round\#1 & 29.10 & 58.57 & 27.04 & 23.63 \\
Ind. C_round\#1 & 28.32 & 54.32 & 23.77 & 18.34 \\
Ind. D_round\#1 & 29.13 & 48.76 & 20.60 & 14.59 \\
Ind. E_round\#1 & 18.28 & 61.48 & 25.12 & 21.46 \\
Ind. A_round\#2 & 23.03 & 59.48 & 23.20 & 18.65 \\
Ind. B_round\#2 & 29.08 & 57.92 & 26.93 & 21.84 \\
Ind. C_round\#2 & 28.31 & 53.97 & 23.63 & 17.94 \\
Ind. D_round\#2 & 29.38 & 48.52 & 20.78 & 14.38 \\
Ind. E_round\#2 & 18.95 & 60.96 & 25.82 & 21.17 \\
\hline \% diff. Ind. A & $0.34 \%$ & $0.51 \%$ & $1.62 \%$ & $1.68 \%$ \\
\% diff. Ind. B & $0.07 \%$ & $1.11 \%$ & $0.40 \%$ & $7.58 \%$ \\
\% diff. Ind. C & $0.02 \%$ & $0.65 \%$ & $0.56 \%$ & $2.14 \%$ \\
\% diff. Ind. D & $0.85 \%$ & $0.49 \%$ & $0.87 \%$ & $1.46 \%$ \\
\% diff. Ind. E & $3.66 \%$ & $0.84 \%$ & $2.78 \%$ & $1.35 \%$ \\
\hline
\end{tabular}

${ }^{a}$ Values are in $\mathrm{cm}^{3}$ for volumes and $\mathrm{mm}^{2}$ for surface areas / Les valeurs sont exprimées en $\mathrm{cm}^{3}$ pour les volumes et en $\mathrm{mm}^{2}$ pour les aires surfaciques.

Table 2 Comparison of volume (V), surface area (SA), and surface area to volume ratio (SA/V) between nasal airways (NA) and nasal cavity (NC) / Comparaison des volumes (V), aire surfacique (SA) et ratio aire surfacique sur volume (SA/V) entre les voies aériennes nasales (NA) et la cavité nasale (NC).

\begin{tabular}{lccr}
\hline & NA V vs. NC V & NA SA vs. NC SA & NA SA/V vs. NC SA/V \\
\hline NC and NA with ethmoidal cells & $0.0445(0.2625)$ & $0.2305(0.0075)$ & $0.0065(0.7066)$ \\
NC and NA lower two thirds & $0.1408(0.0349)$ & $0.7066(0.0001)$ & $0.0078(0.6234)$ \\
\hline
\end{tabular}

${ }^{a}$ Values are coefficients of determination $\left(R^{2}\right)$ and significance after Monte Carlo permutations ( $p$, in parenthesis) / Les valeurs correspondent à des coefficients de determination $\left(R^{2}\right)$ et à la significativité après simulations de Monte Carlo ( $\mathrm{p}$, entre parentheses) 
Table 3 Nasal airways (NA) and nasal cavity (NC) volume (V), surface area (SA), and surface area to volume ratio (SA/V) by sex ${ }^{\mathrm{a}, \mathrm{b}}$ / Volume (V), aire surfacique (SA) et ratio aire surfacique sur volume (SA/V) des voies aériennes nasales (NA) et de la cavité nasale (NC) selon le sexe.

\begin{tabular}{|c|c|c|c|c|c|c|}
\hline & NA V & NCV & NA SA & NC SA & NA SA/V & NC SA/V \\
\hline \multicolumn{7}{|c|}{ Entire nasal airways (NA) and nasal cavity (NC) } \\
\hline M & 22.55 & 63.38 & 24.86 & 21.5 & 1.17E-03 & $3.40 \mathrm{E}-04$ \\
\hline $\mathrm{F}$ & 25.37 & 59.21 & 24.70 & 20.20 & $9.98 \mathrm{E}-04$ & $3.42 \mathrm{E}-04$ \\
\hline M vs. F & $1.27(0.2144)$ & $-1.81(0.0792)$ & $-0.13(0.8982)$ & $-0.14(0.2599)$ & $-2.06(0.0510)$ & $0.11(0.9613)$ \\
\hline \multicolumn{7}{|c|}{ Lower two-thirds of nasal airways (NA) and nasal cavity (NC) } \\
\hline M & 9.90 & 32.85 & 10.82 & 10.69 & $1.20 \mathrm{E}-03$ & 3.27E-04 \\
\hline $\mathrm{F}$ & 11.33 & 30.39 & 10.69 & 10.36 & $1.02 \mathrm{E}-03$ & 3.43E-04 \\
\hline M vs. F & $1.10(0.2736)$ & $-1.4307(0.1656)$ & $-0.18(0.8584)$ & $-0.55(0.5925)$ & $-1.43(0.1575)$ & $1.00(0.3319)$ \\
\hline
\end{tabular}

${ }^{a}$ Values are means in $\mathrm{cm}^{3}$ for volumes and $\mathrm{mm}^{2}$ for surface areas / Les valeurs correspondent à des moyennes en $\mathrm{cm}^{3}$ pour les volumes et en $\mathrm{mm}^{2}$ pour les aires surfaciques.

${ }^{b}$ Values are Student t-values ( $t$ ) and significance after Monte Carlo permutations ( $p$, in parenthesis) / Les valeurs correspondent à des valeurs de test $t$ de Student $(\mathrm{t})$ et à leur significativité après simulations de Monte Carlo ( $\mathrm{p}$, entre parenthèses).

Table 4 Nasal cavity linear measurements by $\operatorname{sex}^{\mathrm{a}, \mathrm{b}}$ / Mesures linéaires de la cavité nasale selon le sexe

\begin{tabular}{|c|c|c|c|}
\hline & NC height & NC width & NC lenght \\
\hline$M$ & 49.2 & 25.8 & 71.2 \\
\hline $\mathrm{F}$ & 47.8 & 25.3 & 69.8 \\
\hline M vs. F & $1.2981(0.2024)$ & $0.8589(0.3950)$ & $0.9827(0.3301)$ \\
\hline
\end{tabular}

${ }^{a}$ Values are means in $\mathrm{mm} /$ Les valeurs correspondent à des moyennes exprimées en $\mathrm{mm}$.

${ }^{b}$ Values are Student t-values $(t)$ and significance after Monte Carlo permutations ( $p$, in parenthesis) / Les valeurs correspondent à des valeurs de test $t$ de Student $(\mathrm{t})$ et à leur significativité après simulations de Monte Carlo ( $\mathrm{p}$, entre parenthèses). 


\section{FIGURE LEGENDS}

Fig. 1 Segmentation of the nasal airways (NA) (A) and nasal cavity (NC) (B). NA and NC are delimited anteriorly by the nasal aperture and posteriorly by the choanae, and were segmented in the transverse plane (upper right) and inspected in the coronal and sagittal planes (lower left and lower right, respectively). Anterior and lateral views of 3D reconstructions of NA (C) and NC (D) / Segmentation des voies aériennes nasales (NA, A) et de la cavité nasale (NC, B). NA et NC sont délimitées antérieurement par l'ouverture nasale et postérieurement par les choanes, et ont été segmentées dans le plan transverse (en haut à droite) et inspectées dans les plans coronal et sagittal (respectivement en bas à gauche et en bas à droite). Vues antérieure et latérale des reconstructions 3D de NA (C) et NC(D).

Fig. 2 Landmarks ( $n=16$ ) were measured on bone to compute the centroid size of the nasal cavity (NC) (antero-lateral view, A; postero-inferior view, B). Lateral view of the reconstructed NC with projected landmarks (C). Sagittal slice used to measure NC height, from, superiorly, the anteriormost point of the inferior surface of the cribriform plate to, inferiorly, the perpendicular projection of the superior point onto the nasal surface of the maxilla (D). The four linear distances measured are represented on the corresponding views / Les landmarks ont été mesurés sur les os afin de calculer la taille centroïde de la cavité nasale (NC) (vue antéro-latérale, $A$; vue postéro-inférieure, B). Vue latérale de NC une fois reconstruite avec les landmarks projetés (C). Coupe sagittale utilisée pour mesurer la hauteur de NC, du point le plus antérieur de la surface inférieure de la plaque cribriforme (point supérieur) au point correspondant à la projection orthogonale du point supérieur sur le maxillaire (point inférieur) (D). Les quatre distances linéaires mesurées sont représentées sur les vues correspondantes. 
Fig. 1

A

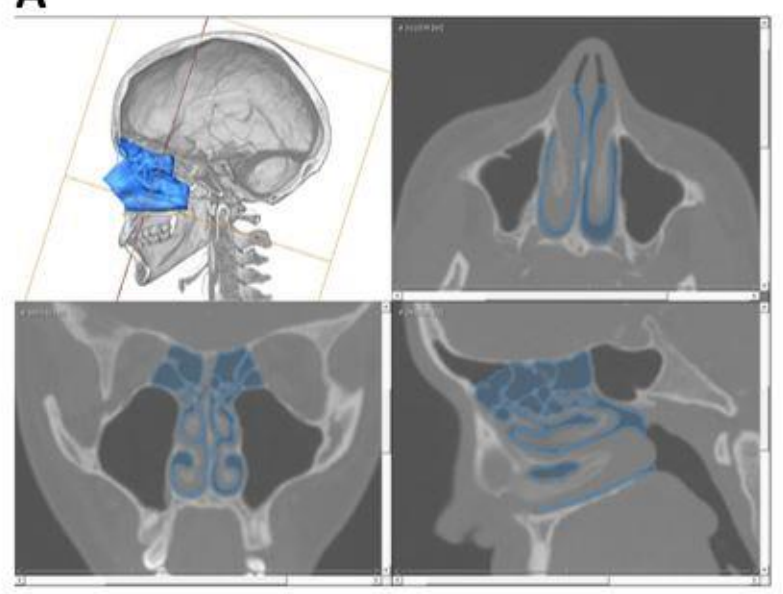

C

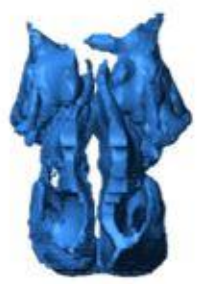

B

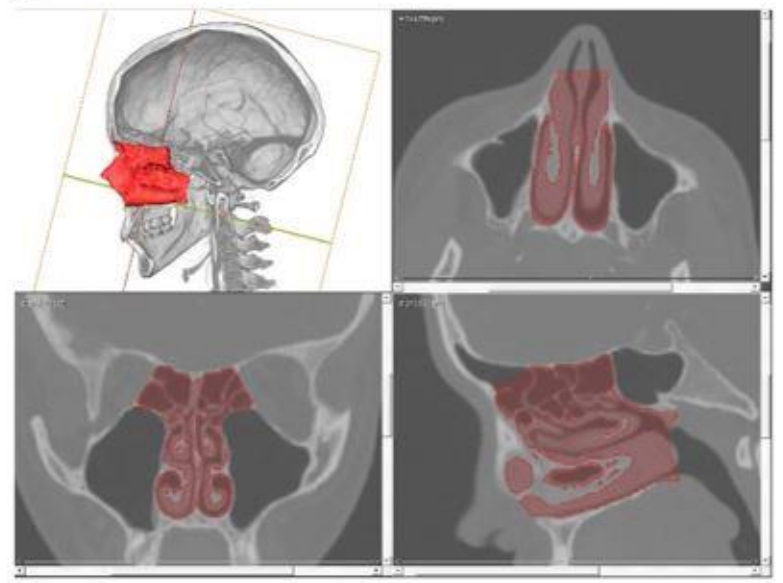

D
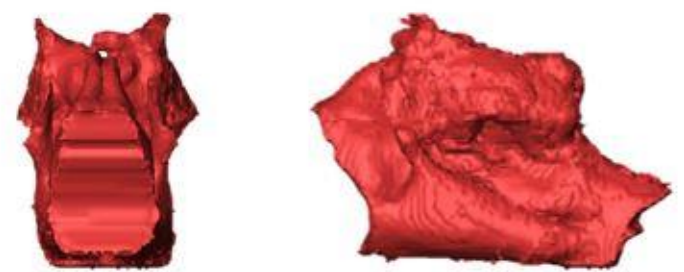
Fig. 2

A

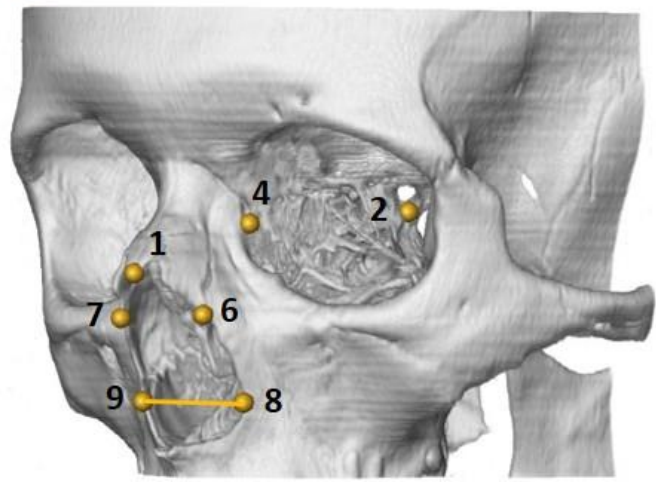

B

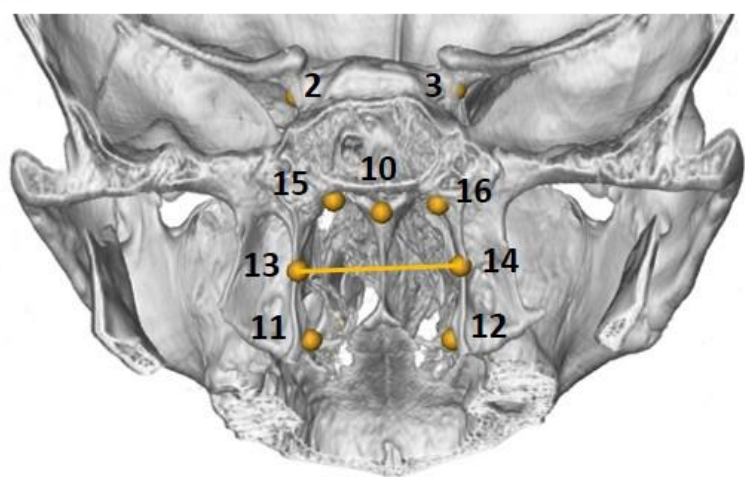

Rhinion (1), Optic canal (2,3), Lacrimal $(4,5)$, Nasomaxillary suture $(6,7)$, Alare $(8,9)$, Hormion (10), Choanal base $(11,12)$, Lower turbinate base $(13,14)$, Choanal roof $(15,16)$

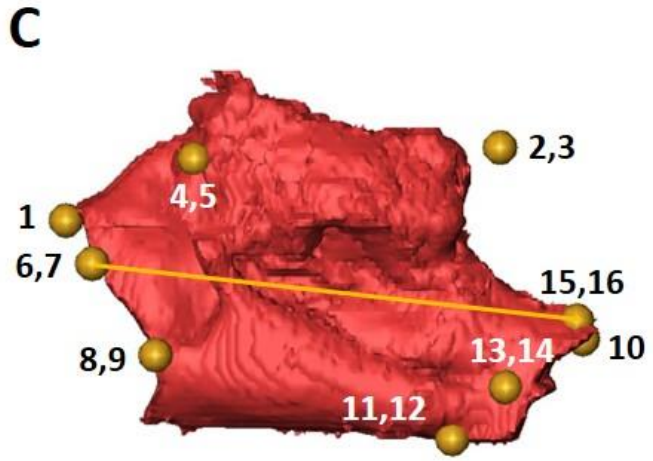

D

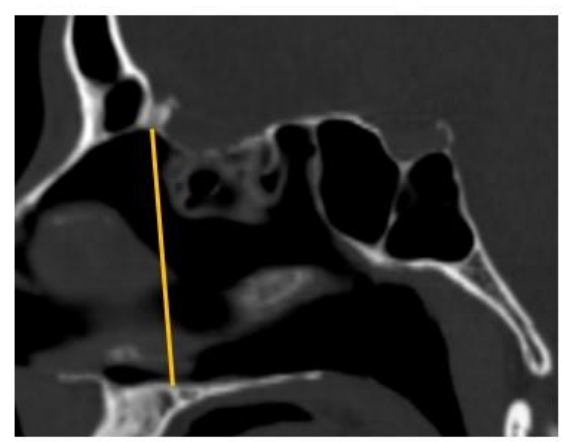

